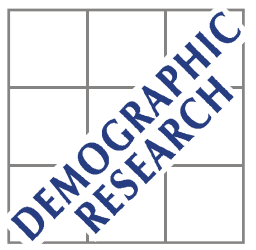

Demographic Research a free, expedited, online journal of peer-reviewed research and commentary in the population sciences published by the Max Planck Institute for Demographic Research Konrad-Zuse Str. 1, D-18057 Rostock · GERMANY www.demographic-research.org

DEMOGRAPHIC RESEARCH

VOLUME 22, ARTICLE 30, PAGES 965-984

PUBLISHED 26 MAY 2010

http://www.demographic-research.org/Volumes/Vol22/30/

DOI: $10.4054 /$ DemRes.2010.22.30

Research Article

\title{
Examining the predictive value of fertility preferences among Ghanaian women
}

Ivy A. Kodzi

David R. Johnson

John B. Casterline

(C) 2010 Ivy A. Kodzi, David R. Johnson \& John B. Casterline.

This open-access work is published under the terms of the Creative Commons Attribution NonCommercial License 2.0 Germany, which permits use, reproduction \& distribution in any medium for non-commercial purposes, provided the original author(s) and source are given credit.

See http:// creativecommons.org/licenses/by-nc/2.0/de/ 


\section{Table of Contents}

1 Introduction $\quad 866$

$2 \quad$ The link between prior fertility preferences and subsequent fertility 967

3 Data and methods $\quad 971$

$4 \quad$ The model $\quad 972$

$5 \quad$ Results 975

$\begin{array}{lll}5.1 & \text { Main effects } & 907\end{array}$

$\begin{array}{lll}5.2 & 912\end{array}$

$6 \quad$ Summary and conclusions $\quad 979$

$7 \quad$ Acknowledgements $\quad 980$

$\begin{array}{ll}\text { References } & 981\end{array}$ 


\title{
Examining the predictive value of fertility preferences among Ghanaian women
}

\author{
Ivy A. Kodzi ${ }^{1}$ \\ David R. Johnson ${ }^{2}$ \\ John B. Casterline ${ }^{3}$
}

\begin{abstract}
Despite extensive research, doubts remain regarding the degree of correspondence between prior stated fertility preferences and subsequent fertility behavior. Preference instability is a factor that potentially undermines predictiveness. Furthermore, if other predictors of fertility substantially explain fertility, then knowledge of preferences may contribute little to explaining or predicting individual fertility behavior. In this study, we examined these aspects of the study of individual fertility preference-behavior consistency. Using a prospective multi-wave panel dataset, we modeled the monthly likelihood of conception, taking into account the dynamic nature of preferences, and controlling for changing reproductive life cycle factors and stable socioeconomic background predictors of fertility. We demonstrate from a sample of fecund married Ghanaian women that fertility preferences retain independent predictive power in the model predicting the likelihood of conception.
\end{abstract}

\footnotetext{
${ }^{1}$ Post-doctoral Research Fellow. African Population and Health Research Center. Shelter Afrique, Longonot Road, Upper Hill. P.O Box 10787, 00100-GPO, Nairobi, Kenya. E-mail: ikodzi@aphrc.org.

${ }^{2}$ Professor. Department of Sociology, Pennsylvania State University. 713 Oswald Tower. University Park, PA 16802. Phone: 814-865-9564. Fax: 814-865-3098. E-mail: drj10@psu.edu.

${ }^{3}$ Professor. Department of Sociology, Ohio State University. 210 Townshend Hall, 1885 Neil Avenue Mall, Columbus, OH, 43210. Phone: 614-247-2519. E-mail: casterline.10@sociology.osu.edu.
} 


\section{Introduction}

Data on fertility preferences have several applications in the family planning field. Fertility preference data are usually used for estimating levels of unmet need for contraception in high fertility settings, estimating the size of markets for contraceptive products, informing strategies for behavior change interventions, explaining aggregate fertility patterns, and, more generally, for understanding childbearing norms in societies (Westoff and Cross 2006; Casterline, El-Zanaty, and El-Zeini 2003; Bongaarts 1990; Westoff 1990). Yet the value of such attitude-based indicators rests on the fundamental belief that attitudes closely reflect actual behavior. Thus, one of the rationales for routinely collecting data on fertility preferences in demographic surveys is the expectation that knowledge of such attitudes may provide some indication of future fertility. However, over the last several decades, demographers have debated the usefulness of such measures of prospective fertility plans for predicting fertility behavior, and this quest to understand how fertility attitudes affect future childbearing behavior has been a remarkably constant feature in the literature.

At the center of the debate about the predictive ability of measures such as intentions, expectations or preferences are two main focal points of skepticism. First, to what extent do people change the attitudes reported in survey interviews after the survey, and before getting pregnant? If preferences change after the survey, then the preference at the time fertility is observed may be different than at the time of the interview (Casterline, El-Zanaty, and El-Zeini 2003; Debpuur and Bawah 2000; Bankole and Westoff 1998). Therefore, analytical difficulties arise when researchers attempt to examine the effect of prior stated attitudes on subsequent fertility by using only one measurement of attitudes, without accounting for possible changes over time. Second, how well do measures of prospective attitudes predict subsequent fertility in comparison to well-known determinants of fertility, particularly life cycle and socioeconomic variables? Do measures of future plans complement conventional predictors of fertility? If attitudinal measures have independent incremental effects on fertility, then they should be included in models predicting or explaining fertility behavior to avoid the problem of omitted variable bias.

Many studies on the relationship between stated fertility intentions or family size expectations and fertility have been carried out in both developed and developing countries (including DaVanzo, Peterson, and Jones 2003; Schoen et al. 1999; Razzaque 2000; Bankole and Westoff 1998; Thomson 1997; Bankole 1995; Tan and Tey 1994; De Silva 1991; Vlassoff 1990; Morgan 1985; Foreit and Suh 1980; Nair and Chow 1980; Hermalin et al. 1979; Westoff and Ryder 1977; Freedman , Hermalin, and Chang 1975). These studies have established that there is considerable correspondence between prior intentions to have additional children and subsequent fertility. Most of 
these studies found that prior attitudes had a statistically significant independent effect on fertility, over and above other determinants of fertility. However, these studies assumed that fertility attitudes were fixed over the study period. Furthermore, while much of the analytical interest has centered on the relative contribution of fertility intentions as a determinant of actual fertility behavior, in most demographic surveys in developing countries, respondents are asked whether they desire (want) additional children. Most theories of planned behavior, however, posit no direct relationship between desires or preferences (as opposed to intentions) and behavioral outcomes.

This paper overcomes the analytical problems outlined above by investigating whether changes in prior fertility preferences affect changes in fertility, while controlling for changes in demographic life cycle and socioeconomic factors. In addition, we assess whether statements about preferences strongly predict subsequent fertility behavior. We investigate the above questions using a prospective longitudinal sample of Ghanaian women who were first surveyed in 1998, and then followed for five years. Eight rounds of reproductive and household surveys were conducted among women who were 18-49 years old at the onset of the study. Monthly pregnancy and contraceptive use data were recorded, in addition to demographic background and household data. The main contribution of this paper is that it provides an analysis of the predictive ability of fertility preferences in a dynamic context. In the following sections, we review the theoretical and empirical literature on the relationship between fertility preferences and fertility, describe the data used for the analysis, and present and offer a discussion of our findings.

\section{The link between prior fertility preferences and subsequent fertility}

Data on fertility preferences may indicate the extent of voluntary control over reproductive outcomes, and are therefore important components in the analysis of individual fertility behavior and aggregate fertility trends (Bongaarts 2003; Schoen et al. 1999; Westoff 1990). The underlying assumption for the expectation that people of reproductive age will have prior, perhaps well-formed childbearing preferences is that there is widespread awareness and availability of reliable contraception. Thus, couples are expected to feel capable of regulating fertility; or, at the very least, they are expected to have the ability to plan their reproductive lives in the short-term. However, there are people who fluctuate in their thinking about whether childbearing is within deliberate personal control; and, admittedly, births do not always result from conscious decisions (Luker 1999). In high fertility societies in particular, the idea of pregnancy planning may not be pervasive, as evidenced by the proportion of people who give non- 
numeric responses like "it is up to God," "as many as possible," or "I don't know" when asked about their desired family size or plans for additional children. More importantly, it is often unclear what constraints or opportunities people have in mind when answering fertility preference questions, and to what extent stated preferences reflect personal plans or goals as opposed to societal expectations. Besides, even when people have clear childbearing preferences, their behavior may not be congruent with prior preferences for various reasons - expectations may be dashed and unanticipated disruptions may occur. What then is the theoretical basis for the link between fertility preference and actual fertility?

We draw on some socio-psychological theories of planned behavior, such as the influential theory of reasoned action and planned behavior (Ajzen and Fishbein 1980; Ajzen 1991), Perugini and Bagozzi's (2001) modification of this theory, Miller and colleagues' (2004) models of fertility decision-making, and other complementary perspectives. The theory of reasoned action and planned behavior (TpB) explains the process that leads to the formation of intentions and the relationship between intentions and subsequent behavior. This theory posits that attitudes towards a behavior, subjective norms, and perceived behavioral control ${ }^{4}$ together affect the intention to act, which in turn directly affect behavior. The three factors affecting intentions are each caused by a set of beliefs, which are determined by factors in the individual's background. According to this theory, intentions, in conjunction with perceived behavioral control, explain most of the variability in planned behavior. Strictly speaking, TpB is a theory about how intentions, rather than preferences or desires, affect behavior.

Intention connotes commitment to a course which usually leads to instrumental behaviors (such as contraceptive use). Desires are, however, wishes, which may be based more on emotions than on reality. For example, an infertile person may want to have a biological child. It appears that, in the fertility literature, the terms fertility "preference" and "intention" have sometimes been used interchangeably. While the word "intention" conceptually has elements of both desire and planning (Stanford et al. 2000), preference relates only to the desire aspect. In developing countries, survey questions are translated into local dialects which may not adequately distinguish between the notions of desire and intention. The Demographic and Health Surveys (DHS) fertility preference measures are usually a combination of two questions. The first question asks whether the respondent wants to have a child. If the response is positive, the second question asks when the child is wanted. Without a question on

\footnotetext{
${ }^{4}$ Attitude is the degree to which performance of the behavior is positively or negatively valued. Subjective norm relates to the perceived social pressure to engage or not to engage in the behavior. In other words, subjective norm is the degree to which people think that most significant others think they should or should not perform the behavior. Perceived behavioral control captures the perception of one's ability to perform the behavior.
} 
timing expectations, the desire to have children would be open-ended and there would be no way to ascertain whether people have realized their desires. But these questions do not necessarily imply deliberate planning. On the one hand, in high fertility societies where contraceptive use is not widespread, people could potentially detach desires from conscious planning, in which case responses to survey preference questions may not reflect purposive behavior. On the other hand, the two-question sequence may communicate the idea of planning and purposive behavior. Thus, the conceptual distinction may not be very clear in practice. Kaufmann, Morris, and Spitz (1997) tested the US National Survey of Family Growth (NSFG) question on pregnancy intentions and the DHS question on pregnancy wantedness using a randomized crossover design in a survey in Arizona. They found that $25 \%$ of the sample gave discordant responses. However, both question types yielded comparable estimates of the level of intended or wanted pregnancy.

Being cognizant of the conceptual difference between preference and intention, we turn to other theoretical perspectives. Perugini and Bagozzi (2001) propose a modification to the theory of reasoned action and planned behavior in which desires are antecedent to intentions, which in turn affect behavior. In this modified model, attitudes, subjective norms, and perceived behavioral control work through desires. Armitage and Conner (2001:471), in a meta-analysis of applications of TpB, confirm Perugini and Bagozzi's finding in their conclusion that "attitude, subjective norm and perceived behavioral control account for significantly more of the variance in individuals' desires than intentions or self-predictions, but intentions were better predictors of behavior." Essentially, Perugini and Bagozzi's modified model suggests that desires/preferences can replace the antecedents of intentions in the TpB model. Therefore, at the individual level, fertility preferences may mediate between background variables and behavior, but this correlation may not be as strong as the intention correlation.

Miller, Severy, and Pasta (2004) also outline a fertility decision-making sequence in which motivations, desires, and intentions affect childbearing behavior. In this framework, childbearing motivations evolve into desires, which may translate into intentions, and which then in turn result in actual behavior. Like $\mathrm{TpB}$ and its modifications, individual desires are posited as antecedent to intentions, and are not expected to be directly related to subsequent fertility. However, there are other perspectives that posit a direct relationship between desires and behavior, essentially arguing that, even though intentions and desires have different motivational strengths, they are closely related in the sense that they both have the potential to generate an action (Bratman 1987; Searle 1983). This interchangeability of concepts is apparent in the empirical literature on fertility attitude-behavior consistency. Many of the 
prospective studies on the predictive validity of fertility plans on subsequent behavior have found modest to strong associations, regardless of how questions were framed.

Furthermore, even though planned behavior theories generally posit that background and life cycle variables have no direct effects on the occurrence of an action, the empirical literature on the determinants of fertility from cross-sectional studies suggests that socioeconomic background characteristics and life cycle factors (age, parity, marital status, marital duration), which are often correlated, are significant independent predictors of both intentions and actual fertility. However, typically, after controlling for intentions, life cycle variables tend to have stronger effects on fertility than variables measuring socioeconomic background in studies examining the predictors of fertility at the individual level.

In analyzing the effect of background variables on fertility, it is important to factor in when these background circumstances occurred in the life course of the individual; i.e., whether these circumstances overlapped with the timing of childbearing preferences and outcomes. While individuals do make deliberate choices about some important aspects of their lives, such as employment, schooling, and place of residence, these choices may not involve a calculated decision to have a child. Background circumstances may not necessarily shape fertility outcomes in the short term. Furthermore, it is possible that some background factors do not directly affect fertility outcomes, as asserted by the psychological theories. It may instead be the case that individuals with certain background characteristics differ from those without those characteristics in ways that have a bearing on their preferences and subsequent fertility. For example, educated women may come from smaller families, or they may have spouses who are equally educated, and who therefore are more likely to share their preference for a smaller family. Educated women may also be more likely to have the fortitude to stick to their preferences even in the face of spousal disagreement. Such traits, which are associated with conventional background factors but are often unobserved, may substantially explain differences in preferences and fertility outcomes. Therefore, to the greatest extent possible, researchers should control for all relevant observed and unobserved factors related to preferences and fertility behavior, especially in models that do not explicitly delineate the causal sequence of the predictors. In practice, it is difficult to control for all background influences, often because the data are not available or the factors are inherently difficult to measure. Moreover, in the case of sub-Saharan Africa, it is, for example, a challenge to search for the causal effect of education on individual fertility behavior over short periods of an adult's life because, for most women, formal schooling is usually completed before the childbearing career begins. Thus, at the individual level, the influence of some of the typical background factors included in fertility models is most likely to have occurred before the start of the childbearing career, and is likely to be relatively stable over time. 
These considerations suggest that, in order to confirm the assumption that preferences play a role in fertility behavior, it is necessary to show that the association between preferences and fertility persists after controlling for all relevant characteristics that potentially confound the relationship. It is possible to control for all observed and unobserved confounding factors that are constant over time which may be associated with preferences or fertility. The fixed-effects regression technique with multi-wave panel data provides a helpful solution. Using the fixed-effects regression method, we are able to reduce omitted-variable bias by comparing the likelihood of pregnancy or birth in the same woman over different situations, thereby isolating the effect of preferences.

In the next section, we delineate the application of the fixed-effects regression method after providing a description of the dataset. We subsequently test whether changes in fertility preferences (coupled with timing expectations) have an independent effect over and above what the effects that can be explained by changes in other predictors of fertility. We expect that changes in fertility preferences will have a statistically significant incremental effect on changes in fertility behavior, controlling for changes in other determinants.

\section{Data and methods}

We used a sample of predominantly rural Ghanaian women of reproductive ages (1849) who were first interviewed in 1998, and were subsequently followed until 2003. The sample was purposively selected from six communities (Agyeman and Casterline 2003). The towns and villages are located in the Central, Western, and Greater Accra regions of Ghana. Demographic, household, and attitudinal data were collected as many as eight times over the period. A total of 1,219 women were interviewed in the first survey. A few months later, a refresher sample of 209 women were added. There was a relatively small reduction in the total sample size by the eighth round, with 1,205 women remaining. At each interview, the women provided information that allowed researchers to update monthly pregnancy and contraceptive use calendars. The dependent variable for the analysis is whether or not pregnancy occurred during the month of observation.

At each round, the women were asked a fertility preference question similar to the ones asked in most Demographic and Health Surveys: "Would you like to have a (another) child with your husband/partner or would you prefer not to have any more children with him?" The possible responses were "wants a (another) child," "wants no more," "cannot get pregnant," "undecided," and "don't know." Women who wanted more children were also asked how soon they wanted to become pregnant. We 
constructed a four-category variable capturing "want pregnancy soon" (this included women who said as soon as possible, or who wanted to have a child within two years. The threshold of two years was adopted following conventional practice in most DHS surveys), "want pregnancy later" (after two years), "want no more children," and "undecided." Women who reported being infertile were excluded from the analysis. The predictor variable of primary interest is the preference response over the multiple rounds.

\section{The model}

Panel data on pregnancy occurrence from the same woman over time provides a means of differentiating between the effects of fertility preferences as an independent factor that influences the woman's behavior. We use the fixed-effects logit model as the statistical framework that accounts for observed and unobserved heterogeneity in a panel setting. We treated time as discrete units in months, where $t=1,2,3 \ldots$ up to the last month of interview. Women were interval censored from the second month of conception until delivery or miscarriage. For each woman i, let $p_{i t}$ be the probability that a pregnancy occurs in month $t$, given that there was no pregnancy in the previous month, and let $F_{i t-1}$ be the woman's fertility preferences stated in the latest interview. $F_{\text {it- }}$ ${ }_{1}$ is coded categorically, as mentioned above. The probability of conception in a given month can be represented by a logistic regression:

$$
\log \left(\frac{p_{i t}}{1-p_{i t}}\right)=\alpha_{i}+\gamma t+\beta F_{i t-1}+\lambda X_{i t}
$$

where $\alpha_{i}$ stands for the woman-specific fixed effects (all stable observed and unobserved characteristics of the woman), $\gamma$ trepresents the effect of time on the logodds of conception - specifically, the duration since the last birth, or, equivalently, the age of the last child, and $\mathrm{X}_{\mathrm{it}}$ a vector of time-varying explanatory variables, which will be defined later. $\lambda$ is the vector of coefficients for the time-varying explanatory variables. In a fixed-effects logit model, $\alpha_{i}$ is differenced out of the probability function, conditional on the sum of the number of conceptions per woman, leaving only the time-varying predictors (Allison 2005; Chamberlain 1980). The basic idea is that, holding the number of conceptions fixed, $\alpha_{i}$ drops from the likelihood function, resulting in a nonlinear relation comparable to the linear probability fixed-effects 
model. Thus, in adjusting for all woman-specific stable traits, the statistical framework models changes in variables over time. Women who did not get pregnant over the entire study period are excluded from the analysis, which potentially affects the statistical power to test parameters. If we were using data from only two points in time for each woman, we would need to include all cases because the covariate and the time effects are perfectly confounded if the sample is limited to only those who get pregnant (Allison 2005). Using women who got pregnant poses no analytical problem because we have multiple covariates at different points in time for each woman, thereby eliminating the complete confounding of time with the occurrence of pregnancy. Our final subsample for the fixed-effects regression therefore consists of 314 fecund and sexually active married women who experienced one or more pregnancies. In addition, for the sake of comparison, we ran a random-effects model, which includes women who did not get pregnant. This is because, in principle, women who did not want to get pregnant, and who, in fact, did not get pregnant, can be said to have acted consistently. However, our interest was also in knowing whether once a woman had changed her mind, her fertility behavior changed accordingly.

As noted above, the fixed effects model allows us to estimate the effects of relevant time-varying covariates of fertility, while controlling for all the stable characteristics of the woman. We included the following control variables in the model: whether the woman had achieved her ideal parity ${ }^{5}$, duration since the last birth coded categorically, marital duration in continuous years, whether the woman had had sex at least once during the month, and, finally, contraceptive use in the month coded nominally by method type (long-term method users include those using more effective methods, such as intra-uterine devices, implants, and injections; short-term users include condom and pill users; and traditional method users include rhythm and withdrawal users). We also controlled for the effect of time between when preferences were stated and when the pregnancy was observed. The more time that has elapsed between when the preference was stated and the behavior, the less predictive preferences may be expected to be. Furthermore, the literature of fertility preferences in sub-Saharan Africa suggests that the partner's preferences, rather than the woman's, may be predictive of actual fertility outcomes (Bankole 1995; Dodoo 1998; Ezeh 1993), and that a woman's preferences are greatly influenced by her partner's preferences. Therefore, we decided to control for partner preferences. However, we did not have direct responses from partners in the dataset; rather, we had the woman's report of her partner's preference. Not surprising, the exploratory analyses showed that there was a

\footnotetext{
${ }^{5}$ The women were asked about their ideal family size in the first round of interviews. We created a timevarying dummy variable capturing the attainment of the ideal parity by comparing actual parity at any given month with the stated ideal. Women who gave non-numeric answers to the ideal parity question were coded as zero with respect to attaining the ideal.
} 
high correlation between a woman's own preferences and her perception of her partner's. Because the two preference variables behaved similarly in the models, we excluded the perceived spousal preference variable. The descriptive statistics of the variables included in the model are presented in Table 1. Consistent with the fertility literature, we expect to find that women who have achieved or exceeded their ideal family size would have a lower likelihood of conceiving, compared to those who have not. We generally expect to see a negative association between duration since the last birth and the likelihood of conception because of decreasing fecundity. Likewise, marriage duration should be negatively associated with fertility. Obviously, women should have a higher likelihood of conception in the months they are sexually active than in the months they are not. We expect to find that contraceptive use is associated with reduced likelihood of conception, with women who use more effective methods having the lowest chances of getting pregnant. We present the empirical findings in the next section.

Table 1: Descriptive statistics of variables included in the fixed effects regression model: subsample of southern Ghanaian married women who had one or more pregnancies, 1998-2003.

\begin{tabular}{lcc}
\hline Variable & Mean (woman-months) & Std. Dev. (woman-months) \\
\hline Had a pregnancy & 0.04 & 0.20 \\
Achieved or exceeded ideal family size & 0.35 & 0.48 \\
Duration since last birth & & \\
Child is 1 year old or less & 0.31 & 0.46 \\
Child is between 1 and 3 years old & 0.36 & 0.48 \\
Child is between 3 and 4 years old & 0.10 & 0.30 \\
Child is over 4 years old & 0.23 & 0.42 \\
Marital duration (years) & 11.17 & 5.88 \\
Coital frequency this month $\geq 1$ & 0.83 & 0.37 \\
Contraceptive use & & \\
User (long-term method) & 0.11 & 0.32 \\
User (short-term method) & 0.13 & 0.33 \\
User (traditional method) & 0.11 & 0.31 \\
Non-user & 0.65 & 0.48 \\
Fertility preference & & \\
Wants to get pregnant within 2 years & 0.19 & 0.39 \\
Wants to get pregnant after 2 years & 0.38 & 0.49 \\
Undecided/don't know & 0.07 & 0.26 \\
Wants no more children & 0.35 & 0.48 \\
Total woman-months $=9711$ & & \\
Total number of women = 314 & & \\
\hline
\end{tabular}

* Range of marital duration is 0.56 to 31.6 years 


\section{Results}

Over the period $1998-2003,29 \%$ of the women had one pregnancy, $16 \%$ had two pregnancies, and $2 \%$ had three pregnancies. Thus, a total of $47 \%$ of the subsample of 1,068 women who were married or in stable unions, and who were neither permanently abstaining from sex nor sterilized, became pregnant at least once over this period. A majority of the women (62\%) who got pregnant during the course of the study reported wanting to have a child the first time they were interviewed. However, a substantial portion of pregnancies $(32 \%)$ occurred among women who said in the first round that they did not want to have more children. These women may have changed their preferences in the course of the study. Likewise, some of those who initially wanted to have a child changed their minds or revised their timing expectations. Thus, fertility preferences were not completely stable over the period. To understand how preference changes may affect changes in fertility behavior, we present a series of regression models, based on the monthly data, which better tease out the effects of such preference changes on the likelihood of pregnancy.

Since this analysis is novel in its application of a fixed-effects regression technique to an analysis of fertility attitude-behavior consistency, we explored the data using a somewhat conventional approach which allows for the direct estimation of the effects of stable background characteristics of the individual. We therefore ran a random-effects logit model which included all women (both those who got pregnant and those who did not) with complete data for the analysis. The results are presented in Table 2. The odds ratios represent the monthly likelihood that a woman would get pregnant compared with a woman who is in the reference category for every variable. While religion and education initially had significant correlations with the likelihood of conception, they (as well as the other socioeconomic variables included) were not statistically significant when we adjusted for reproductive life cycle variables (see columns 1 and 2 of Table 2). In addition, fertility preferences maintain predictive power, but the magnitude of the effect is substantially reduced in the model which controls for both socioeconomic and life cycle background variables (last column of Table 2). The pattern in these results is consistent with what has been found in most empirical studies on fertility intentionbehavior correspondence. Life cycle variables, such as the duration of marriage, the age of the last child, parity, as well as contraceptive use, are strong predictors of future fertility. We now turn to the results of the fixed-effects model, which essentially explores variability within a woman over time. 
Table 2: $\quad$ Random Effects Logistic Regression results showing monthly odds ratios of pregnancy for the sample of southern Ghanaian married women, 1998-2003

\begin{tabular}{|c|c|c|c|}
\hline Variable & Zero order & $\begin{array}{l}\text { Life cycle and other } \\
\text { background variables only }\end{array}$ & Full model \\
\hline \multicolumn{4}{|l|}{ Fertility Preference } \\
\hline Wants to get pregnant within 2 years & $2.95^{\star * *}$ & - & $1.85^{\star \star *}$ \\
\hline Wants to get pregnant after 2 years & $3.13^{\text {***}}$ & - & $1.96^{* \star *}$ \\
\hline Undecided/don't know & $2.19^{\star \star *}$ & - & 1.36 \\
\hline Wants no more children ${ }^{a}$ & & & 1.00 \\
\hline \multicolumn{4}{|l|}{ Religion } \\
\hline Pentecostal Christian & 1.22 & 1.24 & 1.25 \\
\hline Moslem & 1.26 & 1.10 & 1.10 \\
\hline Traditional Religion & 1.30 & 1.14 & 1.13 \\
\hline No Religion & $1.69^{*}$ & 1.13 & 1.15 \\
\hline Orthodox Christian $^{\mathrm{a}}$ & 1.00 & 1.00 & 1.00 \\
\hline \multicolumn{4}{|l|}{ Ethnicity } \\
\hline $\mathrm{Ga}$ & 1.00 & 1.07 & 1.05 \\
\hline Other tribes & 0.82 & 1.05 & 1.06 \\
\hline Akan $^{a}$ & 1.00 & 1.00 & 1.00 \\
\hline \multicolumn{4}{|l|}{ Education } \\
\hline At least some secondary & $0.73^{*}$ & 0.96 & 0.96 \\
\hline Some or completed primary & 1.06 & 1.04 & 1.06 \\
\hline No schooling ${ }^{a}$ & 1.00 & 1.00 & 1.00 \\
\hline \multicolumn{4}{|l|}{ Wealth Index } \\
\hline Top $20 \%$ & 0.89 & 0.82 & 0.81 \\
\hline Middle $40 \%$ & 1.00 & 0.86 & 0.89 \\
\hline Bottom $40 \%{ }^{a}$ & 1.00 & 1.00 & 1.00 \\
\hline Number of living children & $0.82^{* * *}$ & $1.08^{*}$ & $1.16^{\star \star *}$ \\
\hline \multicolumn{4}{|l|}{ Duration since last birth } \\
\hline Child is 1 year old or less & $2.05^{\star \star \star}$ & 1.27 & 1.27 \\
\hline Child is between 1 and 3 years old & $3.21^{* * *}$ & $2.5^{\star \star *}$ & $2.50^{\star * *}$ \\
\hline Child is between 3 and 4 years old & $2.89^{\star \star *}$ & $2.26^{\star \star *}$ & $2.28^{\star * *}$ \\
\hline Child is over 4 years old ${ }^{\mathrm{a}}$ & 1.00 & 1.00 & 1.00 \\
\hline Marital duration (years) & $0.91^{\text {***}}$ & $0.90^{\star * *}$ & $0.90^{* * *}$ \\
\hline Coital frequency this month $\geq 1$ & $1.80^{* * *}$ & $1.97^{\star \star *}$ & $1.88^{\star * *}$ \\
\hline \multicolumn{4}{|l|}{ Contraceptive use } \\
\hline User (long-term method) & $0.06^{\star \star *}$ & $0.04^{\star * *}$ & $0.05^{\star \star *}$ \\
\hline User (short-term method) & $0.14^{\star * *}$ & 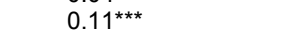 & $0.10^{* * *}$ \\
\hline User (traditional method) & $0.16^{\star \star *}$ & $0.14^{\star * *}$ & $0.15^{\star \star *}$ \\
\hline Non-user ${ }^{a}$ & 1.00 & 1.00 & 1.00 \\
\hline -2Log-likelihood value & -1991.59 & -1801.20 & -1791.13 \\
\hline Probability > log-likelihood ratio & 0.00 & 0.00 & 0.00 \\
\hline Sigma_u & 0.414 & 0.213 & 0.210 \\
\hline Rho & 0.050 & .013 & 0.014 \\
\hline $\mathrm{n}$ (woman-months) & 24468 & 24468 & 24468 \\
\hline $\mathrm{n}$ (women) & 834 & 834 & 834 \\
\hline
\end{tabular}

Note: a represents the reference category for the variable

${ }^{\dagger} p>.10,{ }^{*} p<.05,{ }^{* *} p<.01,{ }^{* * *} p<.001$ 
Table 3: $\quad$ Fixed Effects Logistic Regression results showing monthly odds ratios of pregnancy for the subsample of southern Ghanaian married women who had one or more pregnancies, 1998-2003

\begin{tabular}{|c|c|c|c|}
\hline Variable & Zero order & Life cycle variables only & Full model \\
\hline \multicolumn{4}{|l|}{ Fertility preference } \\
\hline Wants to get pregnant within 2 years & $8.08^{* * *}$ & - & $5.30^{\star *}$ \\
\hline Wants to get pregnant after 2 years & $2.84^{* * *}$ & - & $2.51^{*}$ \\
\hline Undecided/don't know & $2.41^{* *}$ & - & 1.71 \\
\hline Wants no more children ${ }^{a}$ & 1.00 & - & 1.00 \\
\hline Achieved or exceeded ideal family size & $0.19^{* * *}$ & $0.38^{*}$ & $0.41^{*}$ \\
\hline \multicolumn{4}{|l|}{ Duration since last birth } \\
\hline Child is 1 year old or less & $0.13^{* * *}$ & $0.17^{\star \star *}$ & $0.17^{* \star *}$ \\
\hline Child is between 1 and 3 years old & $0.36^{* * *}$ & $0.47^{* *}$ & $0.44^{* *}$ \\
\hline Child is between 3 and 4 years old & 1.16 & 1.09 & 1.02 \\
\hline Child is over 4 years old ${ }^{a}$ & 1.00 & 1.00 & 1.00 \\
\hline Marital duration (years) & $0.83^{* * *}$ & $0.84^{* *}$ & $0.89^{*}$ \\
\hline Coital frequency this month $\geq 1$ & $1.81^{\star *}$ & $2.00^{* *}$ & $1.67^{*}$ \\
\hline \multicolumn{4}{|l|}{ Contraceptive use } \\
\hline User (long-term method) & $0.04^{* * *}$ & $0.06^{* * *}$ & $0.06^{\star * *}$ \\
\hline User (short-term method) & $0.06^{* * *}$ & $0.07^{* * *}$ & $0.06^{\star * *}$ \\
\hline User (traditional method) & $0.12^{* * *}$ & $0.10^{\star \star *}$ & $0.10^{* * *}$ \\
\hline Non-user ${ }^{a}$ & 1.00 & 1.00 & 1.00 \\
\hline Months since last interview & & & 0.96 \\
\hline -2Log-likelihood value & & -1094.76 & -1071.98 \\
\hline Probability $>$ log-likelihood ratio & & 0.000 & 0.000 \\
\hline McFadden's Adj. R-squared & & 0.124 & 0.140 \\
\hline AIC & & 2209.522 & 2169.967 \\
\hline n (woman-months) & 9711 & 9711 & 9711 \\
\hline $\mathrm{n}$ (women) & 314 & 314 & 314 \\
\hline
\end{tabular}

Note: a represents the reference category for the variable.

${ }^{\dagger} p>.10,{ }^{*} p<.05,{ }^{* *} p<.01,{ }^{* * *} p<.001$

The first column of Table 3 shows the zero-order relationships between the timevarying explanatory variables and the likelihood of pregnancy. Not only were fertility preferences strongly predictive of subsequent pregnancy in the bivariate context; the other explanatory variables also had strong significant correlations with pregnancy occurrence. The likelihood of pregnancy was greatest when women wanted to get pregnant soon (in the next two years). However, the model fit statistics show that fertility preferences by themselves explain only a small portion of the variability in the likelihood of pregnancy in a given month. We next investigated the effects of changes 
in background/life cycle variables on the likelihood of pregnancy in a multivariate context. The results are shown in the second column of Table 3. Together, life cycle factors explain a sizeable amount of variability in the likelihood of getting pregnant. The odds of a woman getting pregnant when she had achieved her ideal family size were reduced by about $62 \%$, holding other determinants of fertility constant. Women whose last birth was less than one year ago were less likely to get pregnant than women whose last child was older than age four. Women were also less likely to get pregnant if their youngest child was less than three years old. Marital duration had the expected negative association with the risk of pregnancy, while coital frequency had the expected positive association. We also observe the strong effect of contraceptive use on the likelihood of pregnancy. Women who practiced contraception had a significantly reduced risk of conception, with those using more effective long-term methods having a slightly lower risk.

Comparing the model with only life cycle variables with the full model (last column of Table 3), we observe that the effects of the control variables did not change much when preferences were added to the model. The effects of the woman's fertility preferences were not completely reduced by these variables, as fertility preferences retained an independent and strong predictive power in the model. The odds of conception were 5.3 times higher in months when women wanted to get pregnant soon than when they wanted no more children (95\% CI of 3.2-8.0). If a woman wanted to have a child after two years, the odds of conception were 2.5 times higher than if she wanted no more children (95\% CI of 1.6-4.0). Furthermore, in terms of model fit, the full model is appreciably better than the "background/life cycle only" model, and the estimates fit the data to an appreciable level, as captured by the Hosmer-Lemeshow goodness-of-fit test ${ }^{6}$. It is interesting to note from the models that the timing expectations of the woman indeed made a huge difference in determining the likelihood of pregnancy.

\begin{tabular}{l|rrrc}
\multicolumn{5}{c}{${ }^{6}$ Hosmer-Lemeshow goodness-of-fit test for full model } \\
\hline \multicolumn{4}{|c}{ Conception=1 } \\
\hline Deciles & Prob (HL) & Observed & Expected & Total N \\
1 & 0.0011 & 2 & 1.7 & 2767 \\
2 & 0.0024 & 3 & 4.8 & 2764 \\
3 & 0.0040 & 5 & 8.6 & 2765 \\
4 & 0.0058 & 13 & 13.5 & 2769 \\
5 & 0.0085 & 19 & 19.6 & 2760 \\
6 & 0.0122 & 21 & 28.3 & 2769 \\
7 & 0.0173 & 49 & 40.6 & 2769 \\
8 & 0.0266 & 60 & 60.0 & 2758 \\
9 & 0.0445 & 115 & 93.2 & 2764 \\
\hline $\mathbf{1 0}$ & 0.1197 & 169 & 186.7 & 2763 \\
\hline
\end{tabular}

Hosmer-Lemeshow chi2(8)=12.30, Prob $>$ chi2 $=0.1384$ 


\section{Summary and conclusions}

An underlying rationale for including questions on fertility preferences in demographic surveys relates to the belief that current attitudes affect future behavior. Empirical evidence gathered across the world and over several decades indicates that this assumption is reasonable (Bankole and Westoff 1995; Bongaarts 1992). Fertility preferences collected in survey interviews do not correspond completely with future fertility outcomes at the individual and aggregate levels, but they do provide additional information regarding the future course of fertility. While measures of family size expectation have generally been less predictive, questions regarding the intention to have additional children have shown moderate to strong predictive power. Despite the extensive evidence, areas of doubt remain regarding the impact of preferences on subsequent fertility, and the causal role of preferences in fertility models. First, if a respondent's preferences change after the survey, then the preference at the time fertility is observed may differ from the preference stated at the interview. The extent to which such changes occur undermines the authoritativeness of studies that use only two time points in determining preference or intention-behavior correspondence. Second, if other predictors of fertility substantially mediate between measures of prospective fertility plans and fertility itself, then knowing such plans may be of little value, as preferences may not contribute extra information over and above conventional predictors of fertility. In this paper, we focused on these two aspects of the study of fertility attitude-behavior correspondence using data collected from a sample of women of reproductive age in southern Ghana. Specifically, our analysis tested whether changes in fertility preference triggered changes in fertility behavior, and the extent to which background or life cycle factors mediate between fertility preferences and fertility. The availability of the multi-wave panel data made it possible to take the dynamic nature of preferences into account and to control for all unobserved but fixed covariates of fertility through the use of fixed-effects regression models. We have demonstrated from a subsample of married, fecund women that, controlling for background and life cycle factors, fertility preferences retain independent predictive power in the model predicting the likelihood of conception.

As noted earlier, socio-psychological theories of planned behavior posit at best a weak relationship between preferences and behavior. This study did not test the direct effects of fertility desires mediated by a measure of fertility intentions on subsequent behavior. Our empirical model treated fertility desires and fertility intentions as interchangeable concepts. Yet, because we observe such a strong association between fertility desires and behavior, we are inclined to believe that the sequence of questions eliciting fertility preferences and timing expectations (employed in the Demographic and Health Surveys), may ultimately explore the domain of intentional planning. It 
seems that fertility preference responses reflect some meaningful calculation and expectation of future fertility behavior, and not just mere wishes, which may be unstable over time and uncorrelated with subsequent behavior. Furthermore, the fact that control for conventional covariates of fertility (Table 2) substantially reduced the association between preferences and fertility confirms the presence of selection processes that underlie the association between preferences and fertility. Statistical control for confounding factors did not entirely eliminate the effect, however. Even after controlling for observed and unobserved fixed background factors and observed time-varying life cycle factors, prior fertility preferences were strongly associated with subsequent fertility. These results are consistent with an analytical model in which, independent of other covariates, changes in fertility preferences produce changes in actual fertility. Thus, in line with previous research, we find that knowledge of fertility preferences complements our ability to predict or explain future fertility behavior.

\section{Acknowledgements}

This research was supported by awards to the Policy Research Division of the Population Council from the National Institute of Child Health and Development (R01.HD34524), the Mellon Foundation and the Hewlett Foundation, and an award to the University of Cape Coast from the Rockefeller Foundation. This work began during the first author's doctoral program at the Department of Sociology, Pennsylvania State University. Many thanks to Profs David Shapiro, Gordon De Jong, Michael Massoglia, and Stephen Gyimah, of Queens University, Ontario, Canada for their reviews. 


\section{References}

Agyeman, D.K. and Casterline, J.B. (2003). Social organization and reproductive behavior in southern Ghana. In: Samuel, A.-G. and Casterline, J.B. (eds). Reproduction and social context in sub-Saharan Africa: A collection of microdemographic studies. Westport, CT: Greenwood Press: 7-35. http://www.greenwood.com/catalog/GM1908.aspx.

Ajzen, I. (1991). The theory of planned behavior. Organizational Behavior and Human Decision Processes 50(2): 179-211. doi:10.1016/0749-5978(91)90020-T.

Ajzen, I. and Fishbein, M. (1980). Understanding attitudes and predicting social behavior. Englewood Cliffs, NJ: Prentice-Hall.

Allison, P.D. (2005). Fixed effects regression methods for longitudinal data using SAS. Cary, NC: SAS Institute Inc.

Armitage, C.J. and Conner, M. (2001). Efficacy of the Theory of Planned Behavior: A meta-analytic review. British Journal of Social Psychology 40(4): 471499. doi:10.1348/014466601164939.

Bankole, A. (1995). Desired fertility and fertility behaviour among the Yoruba of Nigeria: a study of couple preferences and subsequent fertility. Population Studies 49(2): 317-328. doi:10.1080/0032472031000148536.

Bankole, A. and Westoff, C.F. (1995). Childbearing attitudes and intentions. Demographic and health surveys comparative studies, no. 17. Calverton, Maryland: Macro International Inc. (DHS comparative studies, no. 17).

Bankole, A. and Westoff, C.F. (1998). The consistency and validity of reproductive attitudes: Evidence from Morocco. Journal of Biosocial Science 30(4): 439-455. doi:10.1017/S0021932098004398.

Bongaarts, J. (1990). The measurement of wanted fertility. Population and Development Review 16(3): 487-506. doi:10.2307/1972833.

Bongaarts, J. (1992). Do reproductive intentions matter? International Family Planning Perspectives 18(3): 102-108. doi:10.2307/2133409.

Bongaarts, J. (2003). Completing the fertility transition in the developing world: The role of educational differences and fertility preferences. Population Studies 57(3): 321-335. doi:10.1080/0032472032000137835.

Bratman, M.E. (1987). Intentions, plans and practical reason. Cambridge, MA: Harvard University Press. 
Casterline, J.B., El-Zanaty, F., and El-Zeini, L.O. (2003). Unmet need and unintended fertility: Longitudinal evidence from Upper Egypt. International Family Planning Perspectives 29(4): 158-166. doi:10.2307/3181044.

Chamberlain, G. (1980). Analysis of covariance with qualitative data. The Review of Economic Studies 47(1): 225-238. doi:10.2307/2297110.

Da Vanzo, J., Peterson, C.E., and Jones, N.R. (2003). How well do desired fertility measures for husbands and wives predict subsequent fertility? Evidence from Malaysia. Asia-Pacific Population Journal 18(4): 5-24. http://www.qascores.org/pubs/drafts/2008/DRU3013.pdf.

De Silva, W.I. (1991). Consistency between reproductive preferences and behavior: The Sri Lankan experience. Studies in Family Planning 22(3): 188-197. doi:10.2307/1966645.

Debpuur, C. and Bawah, A.A. (2000). Are reproductive preferences stable? Evidence from rural Northern Ghana. Genus LVIII (2): 63-89.

Dodoo, F.N.-A. (1998). Men Matter: Additive and Interactive Gendered Preferences and Reproductive Behavior in Kenya. Demography 35(2): 229-242. doi: $10.2307 / 3004054$.

Ezeh, A.C. (1993). The influence of spouses over each other's contraceptive attitudes in Ghana. Studies in Family Planning 24(3): 163-174. doi:10.2307/2939231.

Foreit, K.G. and Suh, M.H. (1980). The effect of reproductive intentions on subsequent fertility among low-parity Korean women, 1971-76. Studies in Family Planning 11(3): 91-104. doi:10.2307/1966005.

Freedman, R, Hermalin, A.I., and Chang, M.-C. (1975). Do statements about desired family size predict fertility? The case of Taiwan, 1967-1970. Demography 12(3): 407-416. doi:10.2307/2060824.

Hermalin, A.I., Freedman, R., Sun, T.-H., and Chang, M.-C. (1979). Do Intentions Predict Fertility? The Experience in Taiwan 1967-74. Studies in Family Planning 10(3): 75-95. doi:10.2307/1965677.

Kaufmann, R.B., Morris, L., and Spitz, A.M. (1997). Comparison of two question sequences for assessing pregnancy intentions. American Journal of Epidemiology 14(9):810-816. $\quad$ http://aje.oxfordjournals.org/cgi/content/ abstract/145/9/810. 
Luker, K.C. (1999). A reminder that human behavior frequently refuses to conform to models created by researchers. Family Planning Perspectives 31(5): 248-249. doi: $10.2307 / 2991574$.

Miller, W.B., Severy, L.J., and Pasta, D. J. (2004). A framework for modeling fertility motivation in couples. Population Studies 58(2): 193-205. doi:10.1080/0032472042000213712.

Morgan, S.P. (1985). Individual and couple intentions for more children: a research note. Demography 22(1): 125-132. doi:10.2307/2060991.

Nair, N.K. and Chow, L.P. (1980). Fertility Intentions and Behavior: Some findings from Taiwan. Studies in Family Planning 11(7/8): 255-263. doi:10.2307/1966243.

Perugini, M. and Bagozzi, R.P. (2001). The role of desires and anticipated emotions in goal-directed behaviours: broadening and deepening the theory of planned behaviour. British Journal of Social Psychology 40: 79-98. doi:10.1348/014466601164704.

Razzaque, A. (2000). Preference for children and subsequent birth: evidence from Matlab, Bangladesh. Genus LVI(3-4): 209-221.

Schoen, R., Astone, N.M., Kim, Y.J., Nathanson, C.A., and Fields, J.M. (1999). Do fertility intentions affect fertility behavior? Journal of Marriage and Family 61(3): 790-799. doi:10.2307/353578.

Searle, J.R. (1983). Intentionality. An essay in the philosophy of mind. New York: Cambridge University Press.

Stanford, J.B., Hobbs, R., Jameson, P., DeWitt, M.J., Fischer, R.C. (2000). Defining dimensions of pregnancy intendedness. Maternal and Child Health Journal 4(3): 183-189. doi:10.1023/A:1009575514205.

Tan, P.T. and Tey, N.P. (1994). Do fertility intentions predict subsequent behavior? Evidence from Peninsular Malaysia. Studies in Family Planning 25(4): 222-231. doi:10.2307/2137905.

Thomson, E. (1997). Couple childbearing desires, intentions, and births. Demography 34(3): 343-354. doi:10.2307/3038288.

Vlassof, C. (1990). Fertility intentions and subsequent behavior: a longitudinal study in rural India. Studies in Family Planning 21(4): 216-225. doi:10.2307/1966616. 
Westoff, C.F. (1990). Reproductive intentions and fertility rates. Family Planning Perspectives 16(3): 84-96. doi:10.2307/2133304.

Westoff, C.F. and Ryder, N.B. (1977). The Predictive Validity of Reproductive Intentions. Demography 14(4): 431-453. doi:10.2307/2060589.

Westoff, C.F. and Cross, A.R. (2006). The stall of fertility transition in Kenya. DHS Analytical Studies, No. 9, Calverton: ORC Macro (DHS Analytical Studies, No. 9). 